\title{
ANALISA SISTEM SUPLAI AIR PRODUKSI DAN AIR PENDINGIN UNTUK KEHANDALAN OPERASI DI PLTU PULANG PISAU (2X66MW)
}

\author{
Hendra Hadi Saputra'), Rudi Siswanto ${ }^{2}$ ) \\ ${ }^{1,2}$ Program Studi Teknik Mesin \\ Fakultas Teknik Universitas Lambung Mangkurat \\ Jl. Akhmad Yani Km. 36 Banjarbaru, Kalimantan Selatan, 70714 \\ e-mail: hh.saputra88@gmail.com
}

\begin{abstract}
This study aims to determine the water supply / discharge system of water pretreatment station equipment which is then processed for the purpose of operating a steam power plant. In the distribution process, the reliability of the equipment and the resulting discharge will be observed whether it is in accordance with the provisions for the ideal operation or not. The expected discharge is $518 \mathrm{m3} / \mathrm{h}$ according to the water balance so that the plant can operate full load (2x66 MW). With this condition, the company is expected to benefit. In the actual conditions this ideal discharge condition is not achieved so that the impact of the plant cannot operate full load $(2 x 66 \mathrm{MW})$. With water conditions that do not match these expectations, it is feared that the company will continue to suffer losses. In fact, this study only obtained a maximum discharge of $402.2 \mathrm{~m} 3 / \mathrm{h}$. From this figure there is a difference in water debit of $115.8 \mathrm{~m} 3 /$ h. Furthermore, this debit shortage must be overcome so that the generator can meet the maximum full load performance. For long-term steps, standby backup equipment must be provided in anticipation of the operation.
\end{abstract}

Keywords: Water Supply, Water Balance, Maximum Discharge, Standby Backup

\section{PENDAHULUAN}

Air adalah kebutuhan yang sangat penting bagi kehidupan, seluruh mahkluk hidup membutuhkan air khusunya manusia, baik itu kebutuhan air minum maupun kebutuhan air bersih untuk kehidupan sehari-hari. air bisa didapatkan dari berbagai sumber, misalnya dari sumur bor, sumur konvensional, air hujan, air laut, sungai dan lain-lain. Selain untuk keperluan hidup sehari - hari, air juga digunakan untuk berbagai keperluan industri salah satunya adalah industri pembangkit listrik yaitu pembangkit listrik tenaga uap (PLTU).

Pada PLTU, air dipanaskan hingga berbuah menjadi uap dengan suhu dan tekanan tertentu lalu kemudian disalurkan untuk memutar turbin uap yang terhubung dengan generator sehingga menghasilkan listrik. Uap yang telah melewati turbin kemudian akan didinginkan sehingga kembali menjadi air yang kemudian akan dipanaskan lagi menjadi uap sehingga membentuk siklus tertutup.

Proses pendinginan uap air ini dilakukan di cooling tower dengan media air dan udara yang ditiupkan menggunakan kipas pendingin. Air yang digunakan sebagai media pendingin ini merupakan bagian dari air pemadam dan air service. Dalam proses pendinginan di cooling tower, air ini akan mengalami penguapan dan terbuang ke atmosfer lepas sehingga air pendingin dan air industri ini akan terus berkurang.

Selain untuk pendingin di cooling tower, air produksi dan air service juga digunakan untuk kebutuhan domestik karyawan di PLTU dan juga ditampung 
sebagai air pemadam kebakaran atau fire fighter. Selain itu, meskipun siklusnya tertutup, air yang digunakan untuk memutar turbin uap juga harus ditambah secara berkala untuk menjaga jumlah dan kualitas airnya. Oleh karena itu, diperlukan sistem suplai air yang memadai agar sistem pembangkit listrik PLTU dapat beroperasi dengan lancar.

Namun, pada kenyataan di lapangan terdapat banyak sekali kendala dalam sistem suplai air tersebut, salah satunya di PLTU Pulang Pisau. Di PLTU Pulang Pisau (2x66 MW) yang berada di daerah Buntoi sampai saat ini belum maksimal produksi air dan penyalurannya, sehingga terkadang di PLTU Pulang Pisau (2x66 MW) masih terkendala dalam kegiatan penyediaan air untuk produksi unit dan untuk penunjang kegiatan operasiona unit. PLTU Pulang Pisau (2x66 MW) menggunakan sumber air dari sungai Kahayan, karena membutuhkan air bersih dalam jumlah yang banyak untuk menunjang kelancaran sarana dan prasarana di PLTU Pulang Pisau (2x66 MW). Namun pada kenyataannya sering terjadi kekurangan air untuk mencukupi kebutuhan air servis dan air produksi di PLTU Pulang Pisau (2x66 MW) sehingga mengganggu proses operasi PLTU Pulang Pisau (2x66 MW).

Berdasarkan uraian di atas bisa disimpulkan bahwa untuk menunjang sistem pembangkit di PLTU Pulang Pisau agar dapat beroperasi dengan baik, diperlukan sistem suplai air produksi dan air pendingin yang memadai. Oleh karena itu, penelitian mengenai Analisa Sistem Suplai Air Produksi dan Air Pendingin untuk kehandalan operasi di PLTU Pulang Pisau (2x66MW) perlu untuk dilakukan.

Mengenai kekurangan sistem suplai air di PLTU Pulang Pisau saat ini dan bagaimana cara mengatasi kekurangan tersebut. Sistem suplai air tersebut dimulai dari air sungai yang diambil dari sungai kalahan sebagai intake water yang kemudian akan diproses sehingga dapat digunakan untuk memenuhi kebutuhan air service di PLTU Pulang Pisau. Air Service ini sendiri antara lain :

1. Living water/domestik water.

2. Air industri/chemical water.

3. Cooling water.

4. Firefighting water.

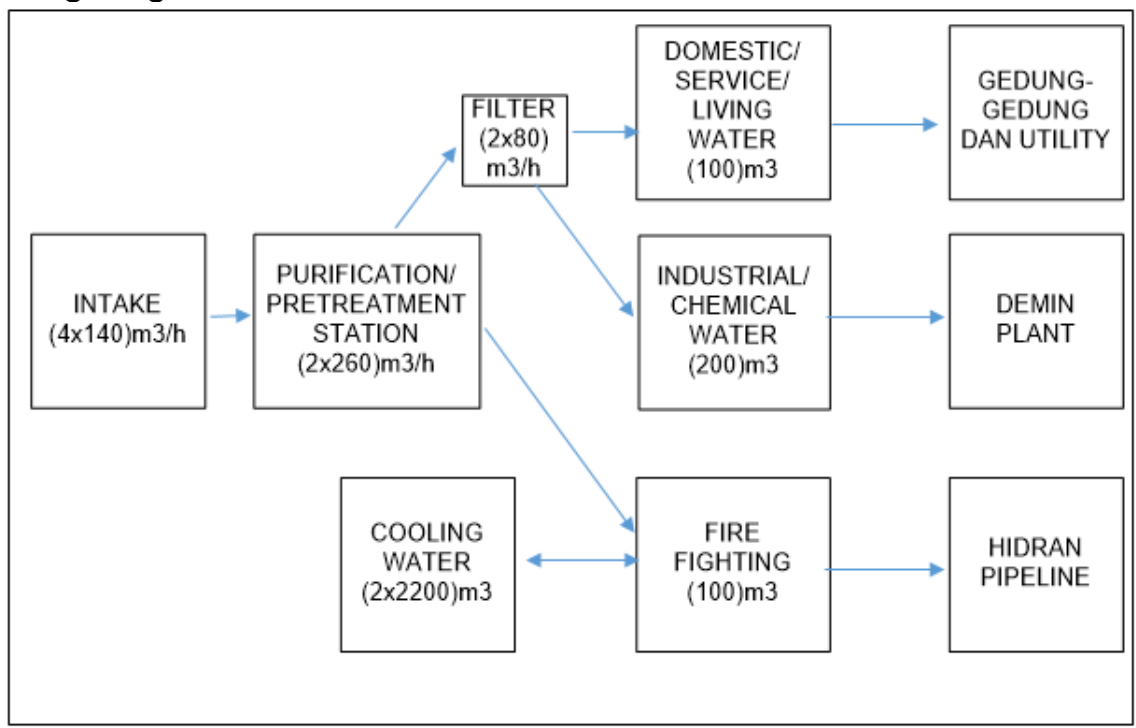

Gambar 1. Bagan Kebutuhan Air PLTU Pulang Pisau (2x66)MW 


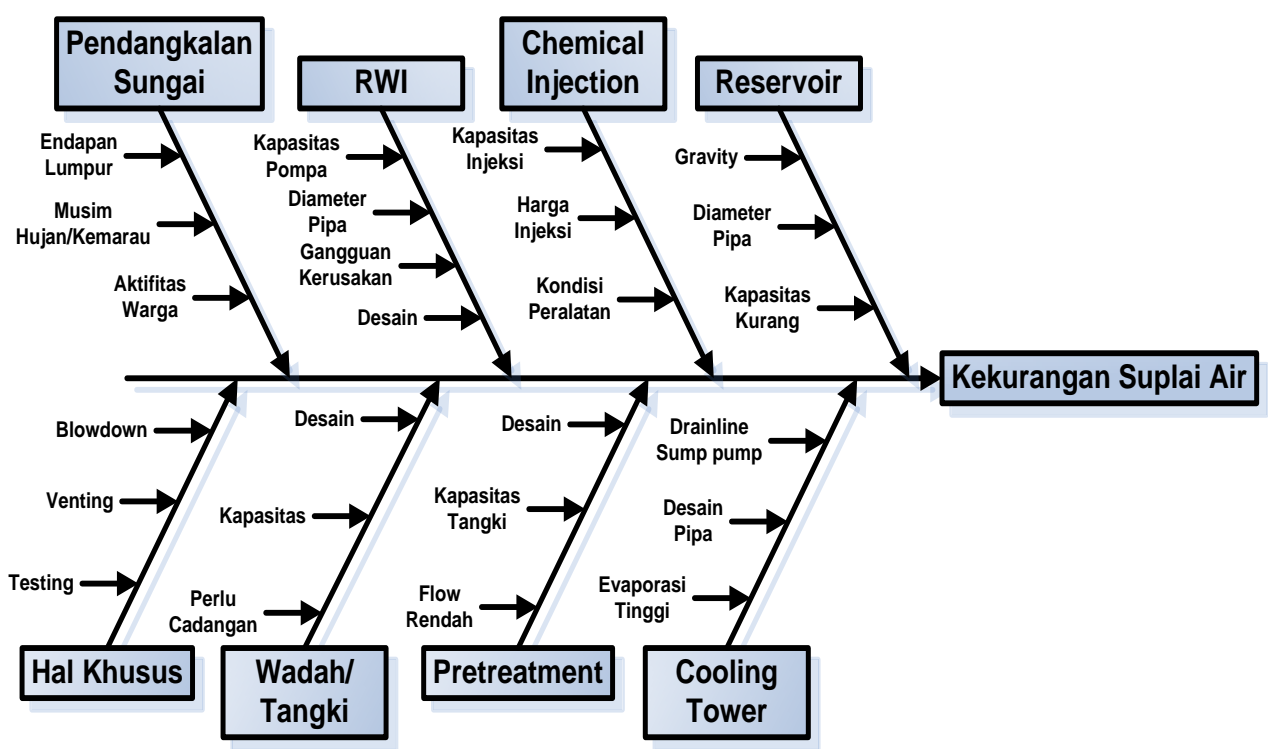

Gambar 2. Fishbone Diagram Kekurangan Air PLTU Pulang Pisau (2x66)MW

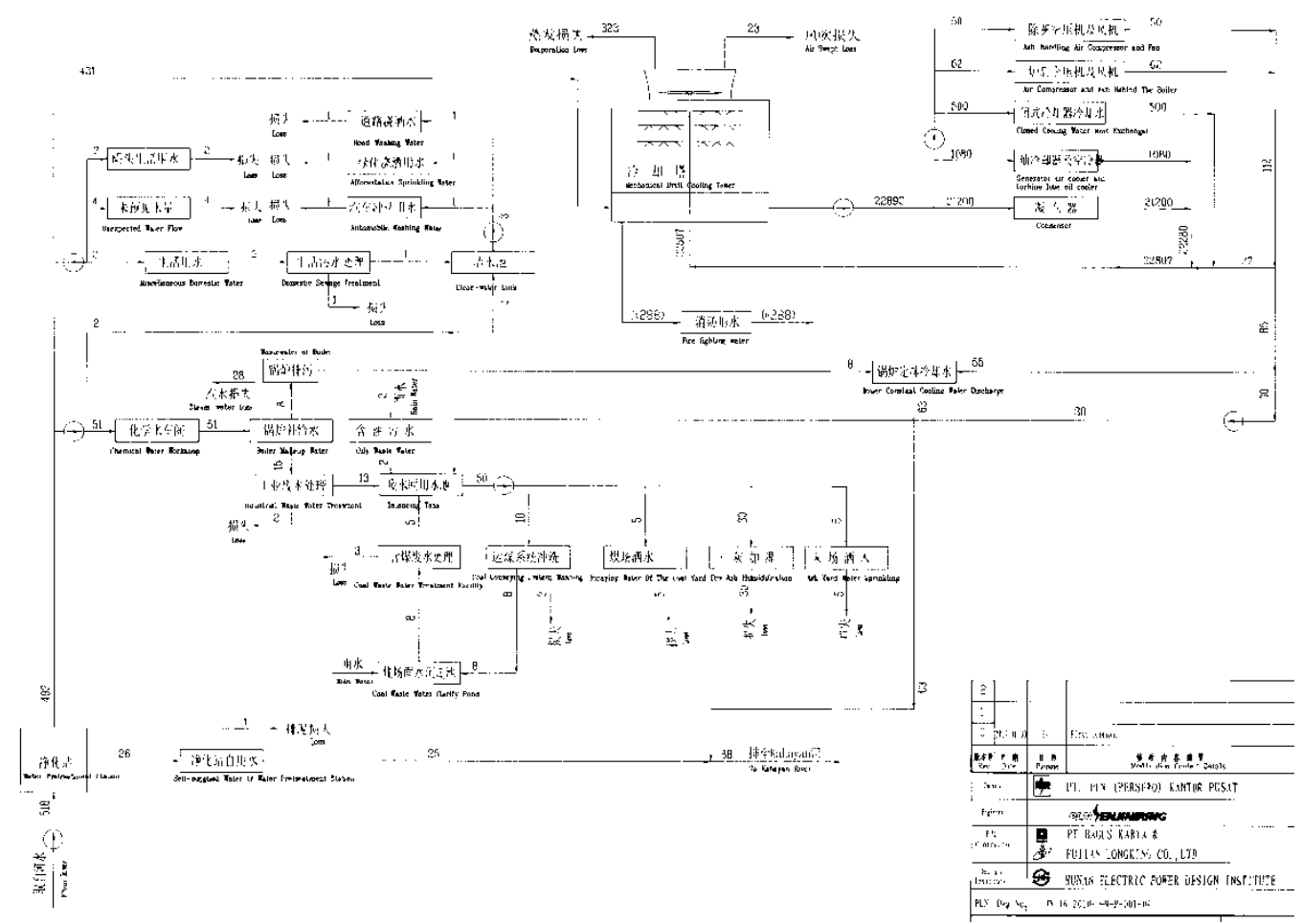

Gambar 3. Kondisi Water Balance PLTU Pulang Pisau (2x66)MW 
Tabel 1. Peralatan water treatment di PLTU Pulang Pisau (2x66) MW

\begin{tabular}{|c|c|c|c|c|c|c|c|}
\hline \multirow{2}{*}{ No } & \multirow{2}{*}{ Description } & \multirow{2}{*}{ Specification } & \multirow{2}{*}{ Unit } & \multicolumn{3}{|c|}{ Quantity } & \multirow[t]{2}{*}{ Remark } \\
\hline & & & & $\# 1$ & \#2 & Total & \\
\hline 1 & Intake Pump & $\begin{array}{l}150 \mathrm{CPP}-23 \mathrm{~A}, \mathrm{Q}= \\
140 \mathrm{~m} 3 / \mathrm{h}, \\
\mathrm{H}=20 \mathrm{~m}, \mathrm{~N}=15 \mathrm{~kW} \\
\mathrm{P}=0,2 \mathrm{Mpa}\end{array}$ & Set & 2 & 2 & 4 & $\begin{array}{l}\text { Hubei } \\
\text { Tongfang } \\
\text { Gaoke Pump } \\
\text { Co. Ltd }\end{array}$ \\
\hline 2 & $\begin{array}{l}\text { Purification/ } \\
\text { Mechanical } \\
\text { Clarifier }\end{array}$ & $\mathrm{Q}=260 \mathrm{~m} 3 / \mathrm{h}$ & Set & 1 & 1 & 2 & $\begin{array}{l}\text { Jiangsu } \\
\text { Peninsula } \\
\text { environmental } \\
\text { enginering } \\
\text { Co.Ltd }\end{array}$ \\
\hline 3 & $\begin{array}{l}\text { Mechanical } \\
\text { draft cooling } \\
\text { tower fan }\end{array}$ & $\begin{array}{l}\mathrm{NH}=4000, \\
\mathrm{Q}=4000 \mathrm{~m} 3 / \mathrm{h} \\
\mathrm{N}=200 \mathrm{~kW}, 6 \mathrm{kV}\end{array}$ & Set & 3 & 3 & 6 & $\begin{array}{l}\text { Jiangsu } \\
\text { Seagull } \\
\text { Cooling Tower } \\
\text { Co. Ltd }\end{array}$ \\
\hline 4 & CW Pump & $\begin{array}{l}800 \mathrm{~S}-22, \\
Q=5693 \mathrm{~m} 3 / \mathrm{h}, \\
H=19 \mathrm{~m}, \\
n=742 \mathrm{r} / \mathrm{min}\end{array}$ & Set & 2 & 2 & 4 & $\begin{array}{l}\text { Shandong } \\
\text { Shuanglun Co. } \\
\text { Ltd }\end{array}$ \\
\hline 5 & $\begin{array}{l}\text { Motor CW } \\
\text { Pump }\end{array}$ & $\begin{array}{l}\text { YKK-8, } \\
\mathrm{n}=740 \mathrm{r} / \mathrm{min}, 6 \mathrm{kV}, \\
500 \mathrm{~kW}, \mathrm{IPS} 54\end{array}$ & Set & 2 & 2 & 4 & $\begin{array}{l}\text { Nanche } \\
\text { Zhuzhou } \\
\text { motor Co. Ltd }\end{array}$ \\
\hline 6 & $\begin{array}{l}\text { Hidraulic } \\
\text { Buterfly Valve }\end{array}$ & $\begin{array}{l}\text { HBD743H-6C, } \\
\text { DN1000, } \\
\mathrm{N}=2,5 \mathrm{~kW}\end{array}$ & Set & 2 & 2 & 4 & $\begin{array}{l}\text { China Valve } \\
\text { Co. Ltd }\end{array}$ \\
\hline 7 & Pipeline Intake & $\begin{array}{l}\text { DN300, } P=1.0 \\
\text { Mpa }\end{array}$ & Set & 1 & 1 & 2 & $\begin{array}{l}\text { Jiangsu } \\
\text { Peninsula } \\
\text { environmental } \\
\text { enginering } \\
\text { Co.Ltd }\end{array}$ \\
\hline \multirow[t]{2}{*}{8} & Fire Pump & $\begin{array}{l}\text { XBD9.0/80- } \\
H S 200, \\
Q=288 \mathrm{~m} 3 / \mathrm{h}, \\
\mathrm{H}=90 \mathrm{~m}\end{array}$ & Set & & & 1 & \multirow{6}{*}{$\begin{array}{l}\text { Anhui Sanlian } \\
\text { Pump Industri } \\
\text { Co. Ltd }\end{array}$} \\
\hline & Diesel Engine & $\begin{array}{l}\mathrm{N}=162 \mathrm{~kW} \\
1500 \mathrm{r} / \mathrm{min}\end{array}$ & Set & & & 1 & \\
\hline \multirow[t]{2}{*}{9} & Fire Pump & $\begin{array}{l}\text { XBD9.0/80- } \\
H S 200, \\
Q=288 \mathrm{~m} 3 / \mathrm{h}, \\
H=90 \mathrm{~m}\end{array}$ & Set & & & 1 & \\
\hline & Electric Engine & $\begin{array}{l}\text { Y3-315S-2, } \\
\text { N=110kW, } \\
\text { 2950r/min, 400V }\end{array}$ & Set & & & 1 & \\
\hline \multirow[b]{2}{*}{10} & $\begin{array}{l}\text { Chemical// } \\
\text { Industrial Water } \\
\text { Pump }\end{array}$ & $\begin{array}{l}\text { IS100-80-160A, } \\
Q=80 \mathrm{~m} 3 / \mathrm{h}, \\
\mathrm{H}=30 \mathrm{~m}\end{array}$ & Set & & & 2 & \\
\hline & Matching Motor & $\begin{array}{l}\mathrm{Y} 160 \mathrm{M}-2, \\
\mathrm{~N}=15 \mathrm{~kW} \\
2900 \mathrm{r} / \mathrm{min}\end{array}$ & Set & & & 2 & \\
\hline
\end{tabular}

METODE PENELITIAN

Adapun metodologi penelitian yang digunakan adalah sebagai berikut. 


\section{Studi literatur}

Studi pustaka yang dilakukan mengenai PLTU, komponen pemipaan suplai air. Studi pustaka ini diperoleh dari sumber beberapa buku maupun jurnal yang didapat di internet.

2. Pengumpulan data

Metode pengumpulan data yang dilakukan adalah dengan mendata dan mencatat seluruh media yang menjadi objek penelitian.

3. Pengolahan data

Data yang telah didapat kemudian dikumpulkan agar dapat dilakukan analisis dalam penelitian tugas akhir ini.

\section{Pengambilan kesimpulan}

Dari hasil analisis data yang didapat selanjutnya dapat diambil kesimpulan mengenai debit dan sistem suplai air untuk produksi (air demin) dan air pendingin di PLTU Pulang Pisau.

Adapun prosedur penelitian dimulai dengan melakukan pengamatan di lapangan yang bertujuan untuk mengidentifikasi masalah yang ada dan langkah selanjutnya yaitu melakukan studi literatur dari buku-buku konstruksi, pemeliharaan, operasi pembangkit dan jurnal online. Selanjutnya peneliti melakukan observasi di lapangan dengan tujuan untuk menjaring data tentang sistem suplai air produksi (air demin) dan air pendingin untuk PLTU Pulang Pisau (2x66 MW), sistem suplai air produksi (air demin) dan air pendingin untuk suatu pembangkit listrik khususnya PLTU Pulang Pisau (2x66 MW), dan kehandalan sistem pemipaan suplai air produksi (air demin) dan air pendingin untuk PLTU Pulang Pisau (2x66 MW). Setelah data didapat dianalisis dan ditarik kesimpulan.

\section{HASIL DAN PEMBAHASAN}

Kondisi ideal jika 4 pompa RWI beroperasi Berdasarkan water balance yang telah dirancang oleh engineer pihak kontraktor, maka pada saat empat buah pompa RWI beroperasi dapat dipenuhi jumlah kebutuhan air sebagai berikut :

Tabel 2. Kondisi 4 pompa RWI (river water intake) beroperasi

\begin{tabular}{|c|c|c|c|c|c|c|}
\hline Penampungan & $\begin{array}{c}\text { Jumla } \\
\text { h } \\
\text { (buah) }\end{array}$ & Dimensi (m) & $\begin{array}{c}\text { Volume } \\
\text { (m3) }\end{array}$ & $\begin{array}{c}\text { Volume } \\
\text { Total } \\
\text { (m3) }\end{array}$ & $\begin{array}{l}\text { Debit } \\
\text { Air } \\
\text { Max } \\
(\mathrm{m} 3 / \mathrm{h})\end{array}$ & $\begin{array}{l}\text { Waktu } \\
\text { Pengisian } \\
\text { per } \\
\text { equipment } \\
\text { (jam) }\end{array}$ \\
\hline Reservoir & 1 & - & - & - & & - \\
\hline Clarifier & 2 & $13 \times 5,5 \times 6$ & 429 & 858 & \multirow{2}{*}{518} & 1,66 \\
\hline Firefighting & 1 & $4 \times 5 \times 5$ & 100 & 100 & & 0,19 \\
\hline Cooling Tower & 2 & $52,8 \times 17,6 \times 2,3$ & 2200 & 4400 & 431 & 10,21 \\
\hline Chemical Pond & 1 & $10 \times 7 \times 3$ & 200 & 200 & \multirow{2}{*}{160} & 1,25 \\
\hline Living water pond & 1 & $5 \times 7 \times 3$ & 100 & 100 & & 0,63 \\
\hline Ultrafiltration Tank & 1 & $(\mathrm{D}=4 ; \mathrm{T}=4)$ & 50 & 50 & \multirow{4}{*}{51} & 0,98 \\
\hline 1st RO tank & 1 & $(\mathrm{D}=4 ; \mathrm{T}=4)$ & 50 & 50 & & 0,98 \\
\hline Intermediate Tank & 1 & $(\mathrm{D}=4 ; \mathrm{T}=4)$ & 50 & 50 & & 0,98 \\
\hline Demin Tank & 2 & $(D=7 ; T=7,8)$ & 300 & 600 & & 11,76 \\
\hline
\end{tabular}




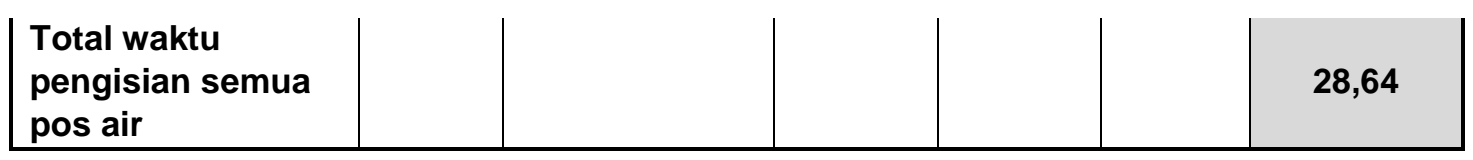

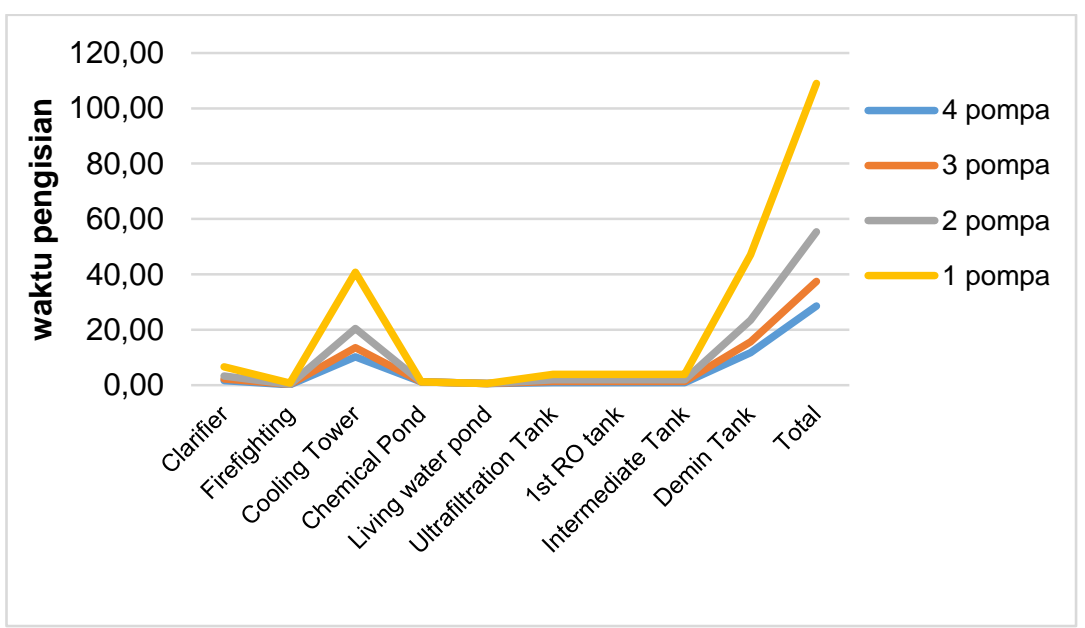

Grafik 1. Perbandingan kinerja terhadap jumlah pompa

\section{Defisit Debit Air Di Clarifier}

Tabel 3. Debit Air Clarifier unit 1

\begin{tabular}{|c|c|c|c|c|c|c|}
\hline Tanggal & $\begin{array}{c}\text { Current } \\
\text { value }\end{array}$ & Max & Min & Average & Pengurang & Aktual \\
\hline $15 / 10 / 2018$ & 211 & 220 & 203 & 211,5 & 60 & 151,5 \\
\hline $16 / 10 / 2018$ & 223 & 250 & 210 & 230 & 60 & 170 \\
\hline $17 / 10 / 2018$ & 235 & 265 & 212 & 238,5 & 60 & 178,5 \\
\hline $18 / 10 / 2018$ & 243 & 255 & 231 & 243 & 60 & 183 \\
\hline $19 / 10 / 2018$ & 243 & 260 & 227 & 243,5 & 60 & 183,5 \\
\hline $20 / 10 / 2018$ & 237 & 245 & 215 & 230 & 60 & 170 \\
\hline $21 / 10 / 2018$ & 252 & 262 & 166 & 214 & 60 & 154 \\
\hline $22 / 10 / 2018$ & 262 & 270 & 245 & 257,5 & 60 & 197,5 \\
\hline & \multicolumn{7}{|c|}{ Rata-Rata } & & 173,5 \\
\hline
\end{tabular}

Tabel 4. Debit Air Clarifier unit 2

\begin{tabular}{|c|c|c|c|c|c|c|}
\hline Tanggal & $\begin{array}{c}\text { Current } \\
\text { value }\end{array}$ & Max & Min & Average & Pengurang & Aktual \\
\hline $15 / 10 / 2018$ & 329 & 490 & 205 & 347,5 & 90 & 257,5 \\
\hline $16 / 10 / 2018$ & 359 & 492 & 241 & 366,5 & 90 & 276,5 \\
\hline $17 / 10 / 2018$ & 305 & 381 & 245 & 313 & 90 & 223 \\
\hline $18 / 10 / 2018$ & 302 & 364 & 239 & 301,5 & 90 & 211,5 \\
\hline $19 / 10 / 2018$ & 317 & 380 & 251 & 315,5 & 90 & 225,5 \\
\hline $20 / 10 / 2018$ & 315 & 360 & 230 & 295 & 90 & 205 \\
\hline $21 / 10 / 2018$ & 309 & 411 & 205 & 308 & 90 & 218 \\
\hline $22 / 10 / 2018$ & 312 & 365 & 240 & 302,5 & 90 & 212,5 \\
\hline
\end{tabular}


Berdasarkan rata - rata dari kedua tabel di atas, maka dapat diketahui total debit aktual di clarifier adalah $402,2 \mathrm{~m}^{3} / \mathrm{h}$. Hal ini tentu saja tidak sesuai dengan debit ideal clarifier pada tabel 4.4 yaitu sebesar $518 \mathrm{~m}^{3} / \mathrm{h}$.

Tabel 5. Kondisi debit air $518 \mathrm{~m}^{3} / \mathrm{h}$

\begin{tabular}{|c|c|c|c|c|c|c|c|}
\hline $\begin{array}{c}\text { Pompa } \\
\text { beroperasi } \\
\text { (buah) }\end{array}$ & $\begin{array}{c}\text { Debit } \\
\text { RWI } \\
(\mathbf{m} 3 / \mathbf{h})\end{array}$ & $\begin{array}{c}\text { Debit } \\
\text { RWI } \\
\text { efisiensi } \\
(\mathbf{m 3} / \mathbf{h})\end{array}$ & $\begin{array}{c}\text { Suplai } \\
\text { ke } \\
\text { Cooling } \\
\text { Tower } \\
(\mathbf{m 3} / \mathbf{h})\end{array}$ & $\begin{array}{c}\text { Suplai } \\
\text { ke } \\
\text { proses } \\
\text { demin } \\
(\mathbf{m} 3 / \mathbf{h})\end{array}$ & $\begin{array}{c}\text { Jumlah } \\
\text { debit } \\
\text { Cooling } \\
\text { tower + } \\
\text { Demin } \\
(\mathbf{m 3} / \mathbf{h})\end{array}$ & $\begin{array}{c}\text { Debit } \\
\text { minor } \\
\text { pos } \\
\text { lain } \\
(\mathbf{m 3} / \mathbf{h})\end{array}$ & $\begin{array}{c}\text { Beban } \\
\text { Pembangkit } \\
(\mathbf{M W})\end{array}$ \\
\hline 1 & 140 & 129,5 & 107,75 & 12,75 & 120,5 & 9 & $(2 \times 16,5)$ \\
\hline 2 & 280 & 259 & 215,5 & 25,5 & 241 & 18 & $(2 \times 33)$ \\
\hline 3 & 420 & 388,5 & 323,25 & 38,25 & 361,5 & 27 & $(2 \times 49,5)$ \\
\hline 4 & 560 & 518 & 431 & 51 & 482 & 36 & $(2 \times 66)$ \\
\hline
\end{tabular}

Pada kondisi ini dijelaskan kondisi ideal debit air pada sistem pembangkit agar dapat mencapai beban operasi penuh sebesar (2x66) MW dan dari produksi listrik ini perusahaan akan mendapatkan untung.

Tabel 6. Kondisi debit air $402,2 \mathrm{~m}^{3} / \mathrm{h}$

\begin{tabular}{|c|c|c|c|c|}
\hline $\begin{array}{c}\text { Pompa } \\
\text { beroperasi } \\
\text { (buah) }\end{array}$ & $\begin{array}{c}\text { Debit } \\
\mathbf{R W I} \\
(\mathbf{m} 3 / \mathbf{h})\end{array}$ & $\begin{array}{c}\text { Suplai ke } \\
\text { Cooling } \\
\text { Tower } \\
(\mathbf{m} 3 / \mathbf{h})\end{array}$ & $\begin{array}{c}\text { Suplai ke } \\
\text { proses } \\
\mathbf{d e m i n} \\
\mathbf{( m 3 / h )}\end{array}$ & Beban Pembangkit ( MW ) \\
\hline 1 & 100,5 & 87,75 & 12,75 & $\begin{array}{c}\text { Demin cukup, Pendingin Cukup } \\
(2 \times 12,8) \text { MW }\end{array}$ \\
\hline 2 & 201 & 175,5 & 25,5 & $\begin{array}{c}\text { Demin cukup, Pendingin Cukup } \\
(2 \times 25,6) \text { MW }\end{array}$ \\
\hline 3 & 301,5 & 263,25 & 38,25 & $\begin{array}{c}\text { Demin cukup, Pendingin Cukup } \\
(2 \times 38,4) \text { MW }\end{array}$ \\
\hline 4 & 402 & 351 & 51 & $\begin{array}{c}\text { Demin cukup, Pendingin Cukup } \\
(2 \times 51,2) \text { MW }\end{array}$ \\
\hline
\end{tabular}

Untuk mencari beban pembangkit dengan kondisi debit air 402,2 $\mathrm{m}^{3} / \mathrm{h}$ tersebut dapat dicari dengan rumus perbandingan/ interpolasi sebagai berikut :

- Kondisi 4 pompa beroperasi

$$
\begin{gathered}
\frac{518}{402,2}=\frac{(2 \times 66)}{X} \\
X=\frac{(132) \times 402,2}{518} \\
X=102,49=(2 \times 51,2) \mathrm{MW}
\end{gathered}
$$

- Kondisi 3 pompa beroperasi

$$
\begin{aligned}
\frac{402,2}{301,5} & =\frac{(2 \times 51,2)}{X} \\
X & =\frac{(102,49) \times 301,5}{402,2}
\end{aligned}
$$


$X=76,82=(2 \times 38,4) \mathrm{MW}$

- Kondisi 2 pompa beroperasi

$$
\begin{aligned}
\frac{301,5}{201} & =\frac{(2 \times 38,4)}{X} \\
X & =\frac{(76,82) \times 201}{301,5} \\
X=51,2 & =(2 \times 25,6) \mathrm{MW}
\end{aligned}
$$

- Kondisi 1 pompa beroperasi

$$
\begin{aligned}
& \frac{201}{100,5}=\frac{(2 \times 25,6)}{X} \\
& X=\frac{(51,2) \times 100,5}{201} \\
& X=25,6=(2 \times 12,8) \mathrm{MW}
\end{aligned}
$$

Pada tabel diatas dapat dijelaskan bahwa penurunan debit dari $518 \mathrm{~m}^{3} / \mathrm{h}$ menjadi $402,2 \mathrm{~m}^{3} / \mathrm{h}$, defisit air sebesar $115,8 \mathrm{~m}^{3} / \mathrm{h}$ berakibat unit pembangkit harus menurunkan beban pembangkit dari $(2 \times 66)$ MW menjadi $(2 \times 51,2) \mathrm{MW}$. Selisih beban pembangkit sebesar $(132-102,4=29,6)$ MW, hal ini tentu merupakan sebuah kerugian bagi perusahaan karena tidak dapat mencapai target produksi listrik.

Jika dihitung dari segi ekonomis maka kerugian 29,6 MW tersebut akan senilai dengan nominal uang berikut ini. Kerugian operasi sebesar 29,6 MW = 29600 KW Harga per KWH tarif dasar listrik sebesar Rp. 1467,28. Kerugian perusahaan dalam 1 jam $=29600 \times 1467,28=43.431 .488,00$ rupiah. Kerugian dalam 1 hari $=24 \times 43.431 .488=1.042 .355 .712,00$ rupiah

\section{Loses Air Akibat Evaporasi di Cooling Tower}

Terlebih dahulu kita hitung efisiensi pompa RWI sebanyak 4 buah. Kapasitas 1 pompa adalah $140 \mathrm{~m}^{3} / \mathrm{h}$, disini terinstal sebanyak 4 buah pompa, maka debit total pompa seharusnya $(4 \times 140)=560 \mathrm{~m}^{3} / \mathrm{h}$. Pada water balance tertulis sebesar $518 \mathrm{~m}^{3} / \mathrm{h}$.

Efisiensi pompa (4 pompa RWI):

$$
\begin{aligned}
& \left.\eta=/ 1-\left(\frac{\text { Qin-Qout }}{\text { Qin }}\right)\right] \times 100 \% \\
& \left.\eta=/ 1-\left(\frac{560-518}{560}\right)\right] \times 100 \% \\
& \eta=[1-(0,075)] \times 100 \% \\
& \eta=92,5 \%
\end{aligned}
$$
$\mathrm{m}^{3} / \mathrm{h}$.

Dari sini maka 1 pompa menyumbangkan debit sebesar $(518: 4)=129,5$

\section{Loses Cooling Tower:}

Debit (Q) in cooling tower sebesar (air masuk ke kolam) : $431 \mathrm{~m}^{3} / \mathrm{h}$

Debit (Q) out looses cooling tower (hilang karena evaporasi/ penguapan) : 323 $\mathrm{m}^{3} / \mathrm{h}$

$$
\begin{aligned}
& \text { Loses }=/ 1-\left(\frac{\text { Qin-Qoutloses }}{\text { Qin }}\right) / \times 100 \% \\
& \text { Loses } \left.=/ 1-\left(\frac{431-323}{431}\right)\right] \times 100 \%
\end{aligned}
$$


Loses $=/ 1-(0,25)] \times 100 \%=75 \%$

Angka $75 \%$ tersebut sangat besar (senilai dengan $323 \mathrm{~m}^{3} / \mathrm{h}$ ) yang dapat diestimasikan mendekati besar debit suplai 3 pompa RWI yaitu $(3 \times 129,5=388,5$ $\mathrm{m}^{3} / \mathrm{h}$ ) Air yang tersisa di kolam sebesar $25 \%$ senilai dengan $108 \mathrm{~m}^{3} / \mathrm{h}$ atau mendekati nilai debit suplai 1 pompa RWI yaitu $129,5 \mathrm{~m}^{3} / \mathrm{h}$.

Dengan demikian dapat disimpulkan bahwa sebenarnya untuk kebutuhan PLTU Pulang Pisau ini disediakan sebanyak 4 pompa RWI yang kapasitasnya ditujukan untuk Cooling tower sebanyak 3 pompa, dan suplai air demin/ air produksi sebanyak 1 pompa saja tanpa adanya cadangan sama sekali. Hal ini dapat berakibat fatal jika ada kerusakan pada salah satu atau beberapa pompa RWI yang dapat mengganggu keseimbangan neraca air atau water balance PLTU Pulang Pisau.

Dampak lebih jauhnya unit pembangkit PLTU Pulang Pisau tidak akan mampu beroperasi pada beban maksimal/ full load karena kekurangan debit/ suplai air. Hal tersebut dijelaskan pada gambar water balance bahwa desain sedemikian rupa itu adalah kondisi mutlak/ persyaratan minimal untuk unit pembangkit PLTU Pulang Pisau dapat beroperasi pada beban maksimal (2x66 $\mathrm{MW}$ )

Tabel 7. Evaporasi dan keringnya kolam yang terjadi di cooling tower

\begin{tabular}{|c|c|c|c|c|c|}
\hline $\begin{array}{c}\text { Pompa } \\
\text { beroperasi }\end{array}$ & $\begin{array}{c}\text { Kapasitas } \\
\text { Cooling } \\
\text { Tower }(\mathbf{m} 3)\end{array}$ & $\begin{array}{c}\text { Suplai Air ke } \\
\text { Cooling } \\
\text { Tower }(\mathbf{m} 3 \mathbf{h})\end{array}$ & $\begin{array}{c}\text { Evaporasi } \\
\text { Rutin } \\
\text { (Losses) } \\
\mathbf{m 3 / h}\end{array}$ & $\begin{array}{c}\Delta \text { Debit } \\
\text { (in-out) } \\
\mathbf{m 3} \mathbf{h}\end{array}$ & $\begin{array}{c}\text { Kondisi } \\
\text { (time) }\end{array}$ \\
\hline 4 & 4400 & 431 & 323 & 108 & Surplus \\
\hline 3 & 4400 & 323,25 & 323 & 0,25 & Imbang \\
\hline 2 & 4400 & 215,5 & 323 & $-107,5$ & $-40,9302$ \\
\hline 1 & 4400 & 107,75 & 323 & $-215,25$ & $-20,4413$ \\
\hline 0 & 4400 & 0 & 323 & -323 & $-13,6223$ \\
\hline
\end{tabular}

- Untuk yang bertanda warna tersebut menunjukkan kondisi beroperasi 2 pompa dan 1 pompa

- Untuk 4 pompa terjadi surplus debit sebesar 108 per jam, surplus air tersebut bisa dialokasikan untuk air demin, dll

- Untuk 3 pompa terjadi hanya imbang saja, artinya tidak bisa memproduksi air demin

- Untuk 2 pompa terjadi delta debit sebesar 107,05 per jam, air Cooling Tower akan habis dalam waktu 40, 93 jam

- Untuk 1 pompa terjadi delta debit sebesar 215,25 per jam, air Cooling Tower akan habis dalam waktu 20,44 jam

- Untuk 0 pompa terjadi delta debit sebesar 323 per jam, air Cooling Tower akan habis dalam waktu 13,62 jam

- Untuk kondisi beroperasi 3 atau 4 pompa masih dalam batas aman untuk Cooling Tower

Pada tabel diatas yang berwarna menunjukkan waktu (jam) durasi habis air pada kolam cooling tower jika dipaksakan beroperasi pada beban tinggi (2x66) MW. Untuk menghindari keringnya air pendingin maka dapat diatasi dengan cara 
menurunkan beban operasi pembangkit/ derating. Namun pada sistem jaringan kelistrikan di Kalimantan ini suatu pembangkit selalu dituntut untuk beroperasi beban penuh dan tidak diizinkan derating karena defisit sistem kelistrikan di wilayah Kalimantan.

Kondisi aktual di PLTU Pulang Pisau yang telah diuraikan di atas, dapat dibuat grafik perbandingan seperti berikut :

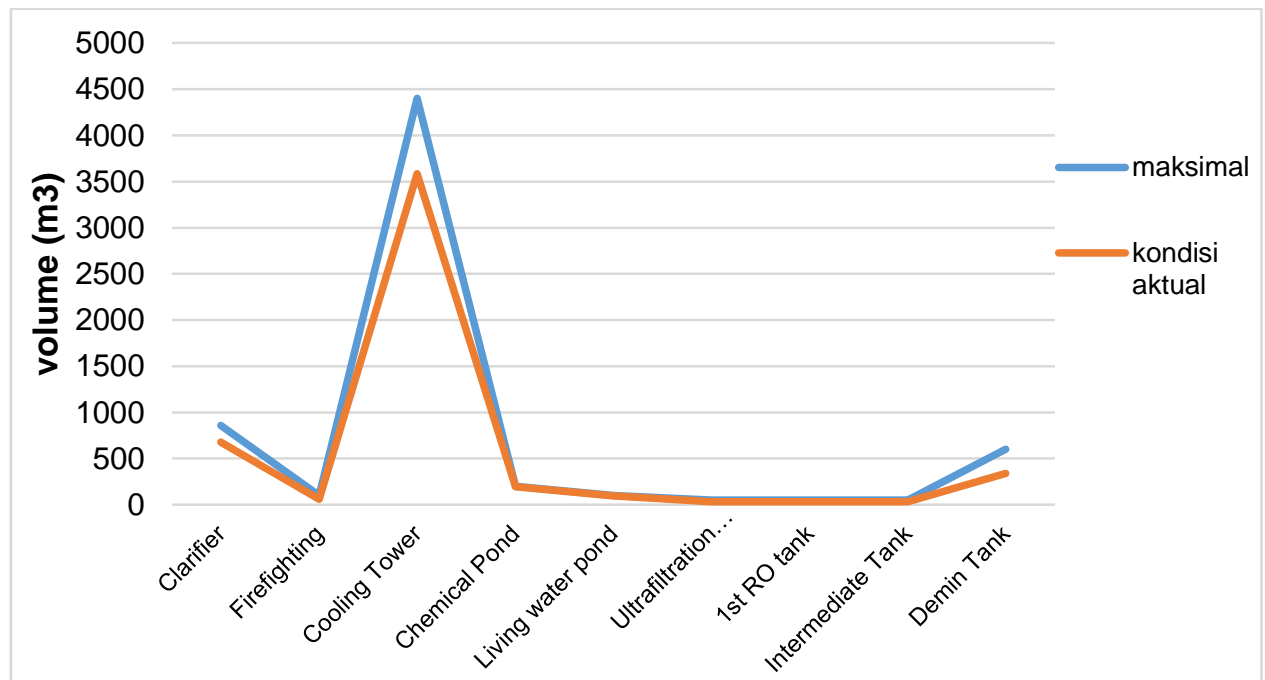

Grafik 2. Perbandingan kondisi maksimal dan kondisi aktual volume air di PLTU Pulang Pisau

Tabel 8. Output pembangkit PLTU Pulang Pisau bulan Oktober

\begin{tabular}{|c|c|c|c|c|c|c|c|c|}
\hline \multirow{2}{*}{ Tanggal } & \multicolumn{4}{|c|}{ Unit 1 (MW) } & \multicolumn{4}{c|}{ Unit 2 (MW) } \\
\cline { 2 - 10 } & $\begin{array}{c}\text { Current } \\
\text { Value }\end{array}$ & Max & Min & Average & $\begin{array}{c}\text { Current } \\
\text { Value }\end{array}$ & Max & Min & Average \\
\hline $14 / 10 / 2018$ & 50 & 53 & 46 & 49,5 & 50 & 53 & 49 & 51 \\
\hline $15 / 10 / 2018$ & 51 & 51 & 49 & 50 & 51 & 52 & 47 & 49,5 \\
\hline $16 / 10 / 2018$ & 50 & 51 & 48 & 49,5 & 50 & 52 & 49 & 50,5 \\
\hline $17 / 10 / 2018$ & 50 & 52 & 47 & 49,5 & 50 & 52 & 49 & 50,5 \\
\hline $18 / 10 / 2018$ & 50 & 51 & 48 & 49,5 & 50 & 52 & 49 & 50,5 \\
\hline $19 / 10 / 2018$ & 51 & 51 & 48 & 49,5 & 51 & 51 & 48 & 49,5 \\
\hline $20 / 10 / 2018$ & 50 & 52 & 48 & 50 & 50 & 52 & 48 & 50 \\
\hline $21 / 10 / 2018$ & 49 & 51 & 28 & 39,5 & 51 & 51 & 12 & 31,5 \\
\hline $22 / 10 / 2018$ & 51 & 52 & 49 & 50,5 & 50 & 51 & 49 & 50 \\
\hline $23 / 10 / 2018$ & 51 & 51 & 48 & 49,5 & - & - & - & - \\
\hline $24 / 10 / 2018$ & 50 & 51 & 34 & 42,5 & - & - & - & - \\
\hline $25 / 10 / 2018$ & 50 & 52 & 49 & 50,5 & - & - & - & - \\
\hline $26 / 10 / 2018$ & 50 & 51 & 34 & 42,5 & - & - & - & - \\
\hline $27 / 10 / 2018$ & 35 & 51 & 35 & 43 & - & - & - & - \\
\hline $28 / 10 / 2018$ & 50 & 51 & 49 & 50 & - & - & - & - \\
\hline $29 / 10 / 2018$ & 50 & 51 & 49 & 50 & 47 & 41 & 19 & 30 \\
\hline
\end{tabular}






Grafik 3. Output PLTU Pulang Pisau bulan Oktober

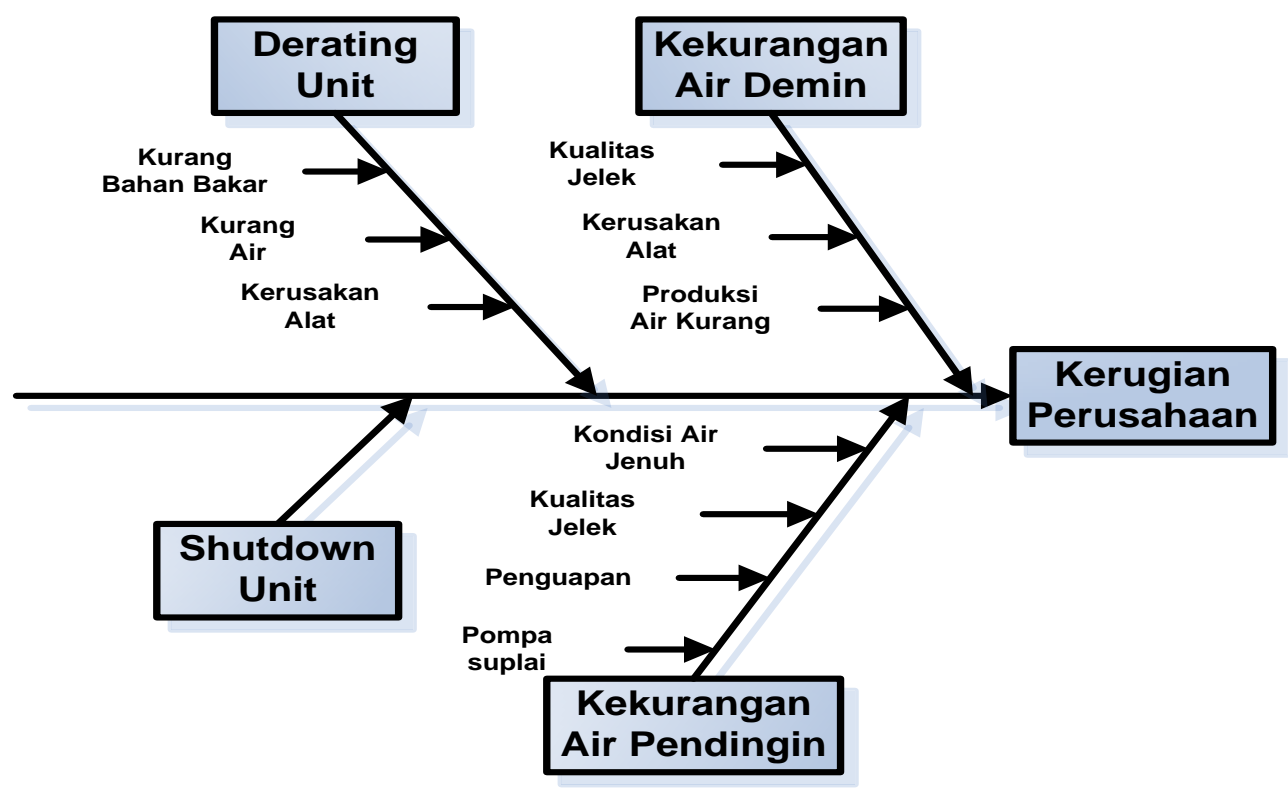

Gambar 4. Fishbone diagram dampak dari defisit air di PLTU Pulang Pisau

\section{Solusi Jangka Pendek}

1. Pemasangan total flow outlet demin tank

2. Pemasangan flowmeter di RWI

3. Kalibrasi ( normalisasi) flowmeter di area WTP

4. Menyiapkan cadangan peralatan kritis di WTP

5. Pengecekan secara berkala untuk parameter - parameter cleaning reverse osmosis dan ultrafiltration

6. Pemasangan alat silt density index (SDI) pada inlet reverse osmosis

7. Aktifkan injeksi sesuai dengan design line tapping position

8. Jar test dengan jenis koagulan yang berbeda

9. Aktifkan unit sludge dewatering

10. Penambahan RWI atau normalisasi flow RWI

11. Pengecekan kemampuan ion exchanger resin dan jumlah resin 
12. Penambahan atau memperbesar kapasitas cartridge filter untuk primary dan secondary reverse osmosis

\section{Solusi Jangka Panjang}

1. Penambahan tangki demin

2. Penggunaan kembali air dari WWTP

3. Penambahan tangki dan pompa air untuk makeup cooling tower

4. Penambahan coating/lining di clarifier

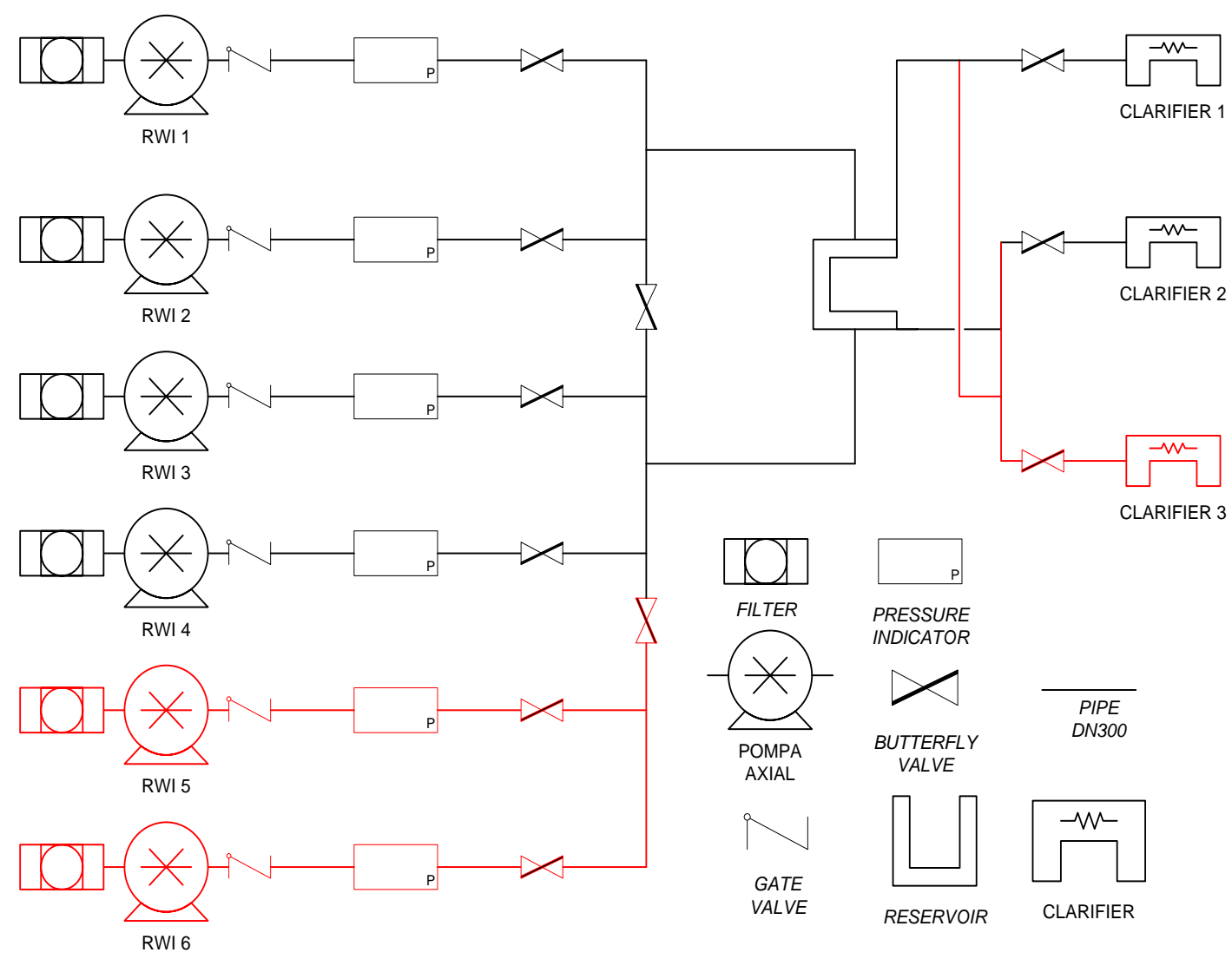

Gambar 5. Instalasi tambahan RWI dan Clarifier

\section{Pembahasan}

Pada water pretreatment station, aliran air dibagi menjadi dua yaitu self supplied water of water pretreatment station sebesar $26 \mathrm{~m}^{3} / \mathrm{h}$ dan air untuk kebutuhan operasi (cooling tower, miscelenous domestic water, chemical water workshop) sebesar $492 \mathrm{~m}^{3} / \mathrm{h}$.

Pada penelitian ini yang akan dibahas adalah yang telah mengalami proses water treatment dan akan digunakan untuk kebutuhan operasi beserta losesnya. Dari kebutuhan operasi itu sendiri $492 \mathrm{~m}^{3} / \mathrm{h}$ dipecah menjadi 3 antara lain :

1. Cooling tower sebesar $431 \mathrm{~m}^{3} / \mathrm{h}$

2. Miscelenous domestic water sebesar $8 \mathrm{~m}^{3} / \mathrm{h}$

3. Chemical water workshop sebesar $53 \mathrm{~m}^{3} / \mathrm{h}$

Yang menjadi hal mayor disini adalah kebutuhan suplai cooling tower dan chemical water workshop (bahan air demin) karena 2 air ini sangat besar pengaruhnya terhadap kelangsungan operasi PLTU. 
Pada rancangan water balance PLTU Pulang Pisau (F6101S-S0101-04) juga dijelaskan tentang loses yang terjadi pada siklus air di PLTU Pulang Pisau. Loses tersebut antara lain :

1. Evaporasi pada cooling tower sebesar $323 \mathrm{~m} / \mathrm{h}$; hal ini sudah pasti terjadi secara continue saat semua fan cooling tower beroperasi mendinginkan air pendingin return dari condensor jika air tidak didinginkan maka temperatur pada condensor akan buruk

2. Loses pada boiler venting dan blowdown sebesar $28 \mathrm{~m}^{3} / \mathrm{h}$; ini masih bisa lebih besar lagi jika ada kondisi khusus misalnya saat tiba-tiba kondisi air boiler sangat buruk dan harus dilakukan blowdown dalam jumlah besar atau saat kondisi akan dilakukan firing unit harus dilakukan flushing pada seluruh line boiler.

3. Pada PLTU Pulang Pisau terdapat dua clarifier yang memiliki kapasitas $2 \times 260 \mathrm{~m}^{3} / \mathrm{h}$. Dari pengukuran di lapangan, hal tersebut tampak terdapat kekurangan debit air yang disebabkan kinerja pompa, dan ditambah lagi selisih pengukuran antara pembacaan flow meter di monitor CCR dan kondisi flow meter sesungguhnya di lokal, oleh karena itu jumlah debit air di monitor CCR harus dikurangi yaitu sebesar $60 \mathrm{~m}^{3} / \mathrm{h}$ untuk clarifier 1 dan 90 $\mathrm{m}^{3} / \mathrm{h}$ untuk clarifier 2 .

4. Total debit aktual di clarifier adalah $402,2 \mathrm{~m}^{3} / \mathrm{h}$. Hal ini tentu saja tidak sesuai dengan debit ideal clarifier $518 \mathrm{~m}^{3} / \mathrm{h}$.

\section{KESIMPULAN}

Dari hasil pengamatan dan penelitian yang dilakukan di PLTU Pulang

Pisau (2x66 MW), maka dapat diambil kesimpulan sebagai berikut:

1. Kebutuhan suplai air produksi dan air pendingin untuk kehandalan operasi PLTU Pulang Pisau (2x66 MW) menggunakan 4 buah pompa kapasitas masing-masing $140 \mathrm{~m}^{3} / \mathrm{h}$ dan 2 buah clarifier.

2. kondisi aktual debit air produksi dan air pendingin di PLTU Pulang Pisau (2x66 MW) mengalami kekurangan debit air sebesar $79,32 \mathrm{~m}^{3} / \mathrm{h}$ (berdasarkan data percobaan PJB tahun 2017) dan $115,8 \mathrm{~m}^{3} / \mathrm{h}$ dari penelitian penulis pada Oktober 2018. Dari loses debit $115,8 \mathrm{~m}^{3} / \mathrm{h}$ maka PLN mengalami kerugian 29,6 MW atau setara 1.042.355.712,00 rupiah/ hari.

3. Untuk mengantisipasi kekurangan ketersediaan suplai air dengan menambah 2 pompa beserta instalasi pemipaanya dan 1 buah clarifier. 


\section{DAFTAR PUSTAKA}

Al-Layla, M. A., 1978, Water Supply Engineering Design, Ann Arbor Science Mich, Michigan.

Benefield, LD., 1982, Process Chemistry for Water and Wastewater Treatment, Prentice Hall, Inc., New Jersey.

Darma, Surya, 2013, Rancang Bangun pompa Hidraulik Ram (Hydram). Tugas Akhir, Universitas Sumatera Utara, Medan.

Ervianto, W. I., 2005, Manajemen Proyek Konstruksi, Andi, Yogyakarta.

Franzini Joseph B., Finnemore E. John., 2002. Fluid Mechanics, The McGrawHill Companies, Inc., New York. 